\title{
REGIONAL PLANNING MODELS IN ORDER TO STIMULATE THE RESEARCH-DEVELOPMENT AND INNOVATIVE ACTIVITIES
}

\author{
PhD Daniela Antonescu, Scientific researcher rank II in field of regional development, Institute of \\ national Economy, \\ e-mail:da_antonescu@zappmobile.ro
}

\begin{abstract}
The regional policy is a key element of the EU 2007-2013 strategy for economic growth and jobs and innovation is placed in the middle of all these efforts. This way, it is offered an important support to innovation within different regions and member states. The EU regional policy must respond to globalization challenges and expansion opportunities. The next generation of regional programs must be in conformity with the Lisbon Agenda requirements for economic growth and jobs, that is why it is necessary to reorganize it according to the other policies and priorities. The competitiveness and economic growth objectives are implemented at all levels: local, regional and national.

The regional programs had and will finance many innovative activities in every sector: economical, social, cultural, technological. In fact, they supported pilot-projects which intended innovation in certain sectors and which were extended successfully on a large scale. New partners and methods were encouraged to move in on innovation field: enterprises, universities, research centers, public authorities.
\end{abstract}

Keywords: regional innovation, plan of regional development

JEL Codes: R1, R10, R11

The regional policy is a key element of the EU 2007-2013 strategy for economic growth and jobs and innovation is placed in the middle of all these efforts. This way, it is offered an important support to innovation within different regions and member states. The EU regional policy must respond to globalization challenges and expansion opportunities. The next generation of regional programs must be in conformity with the Lisbon Agenda requirements for economic growth and jobs, that is why it is necessary to reorganize it according to the other policies and priorities. The competitiveness and economic growth objectives are implemented at all levels: local, regional and national.

The regional programs had and will finance many innovative activities in every sector: economical, social, cultural, technological. In fact, they supported pilot-projects which intended innovation in certain sectors and which were extended successfully on a large scale. New partners and methods were encouraged to move in on innovation field: enterprises, universities, research centers, public authorities. These methods are based on EU experience and are already in use in order to increase the regional growth.

Today, the regions and member states have finalized the project for the Common Frame Work and the Operational Programs 2007-2013. Innovation was considered a priority in many of those programs and will become a strategic element of the regional development strategies.

\section{Inovation on a regional scale - requirement of the social and economical cohesion policy}

EU regions are facing these days' new challenges. Opening the EU economies equals growth in competitiveness and in competition from other markets, especially from Southeast Asia.

Growth in trade globalization is affecting comparative advantages and stimulates activities division: increase in externalizing services and relocation of low benefit in intensive work activities 
(ex: textile sector), public services and research activities. Spreading informations and communications technology is increasing this phenomenon by reducing constraints due to market proximity in choosing the location of the enterprise.

Regions are not distributed in this new competition and they see this through their own capacity of generating innovation. In the open economy competitiveness, arise no more from costs and natural advantages but from enterprise capacity to create new added value for services and goods responding to the requests of the market. They must respond to changes not only by developing services and good but also by market research and organizing production, distribution, marketing and improvement.

Enterprises need quality services sources because innovation depends on quality cooperation between a big number of enterprises and organizations with complementary competencies.

Competitive sectors are not the only interested in innovation. Improving the quality and effectiveness of the low exposed sectors (education, health, and administration) is also a possible result of a partnership experience.

Developed regions and metropolitan areas can adapt to globalization. There big demand for goods and services of high quality stimulates high-tech activities, which enhance information, knowledge and survey and allow this way naturalizing of the innovations.

Less developed regions can use their comparison advantages in labor force costs to win productive investments. This will stimulate growth, on a short scale, but it is necessary to support it through other means as well as strong economic sectors policies to facilitate interaction between innovation actors. On a large scale, it emphasizes the dynamics, competitiveness and international attractiveness.

\subsection{New approaches}

During the last 15 years, understanding innovation developed quite a lot. The vision on innovation became systemical and straight (innovation comes out of research laboratories and it is exploited by enterprises and communities). Innovation arose above everything else as concerns interaction quality between producers, users and intermediators of knowledge in the regions: local authorities, companies, production centers or knowledge transfer, local coordination institutions, SME or R\&D financing agencies and others.

EU regions are very different regarding innovation. Dividing territory, culture, values and common facilities, project unification allowed cluster development ${ }^{1}$. These divergences increased because of the expansion ${ }^{2}$. Abilities, infrastructure and assets needed for innovation are placed in advanced regions, which own a great variety of actors and important links. Organizing this kind of innovative systems in order to be also transparent and reactive is a difficult task mostly because of the institutional complexity of the European democracies. However, by imitation, the region complexity may improve their economy and may develop a greater adaptability to a permanently changing environment.

The most advanced regions have the best analytical capacity to identify prioritary sectors, which need to focus on; usually those with strong potential and dynamics, also taking into account the general scientific and technological support for future activities. These regions are developing and targeting to the constant increase of knowledge based on the innovative system at local or national level, which may strengthen and be useful to them in order to develop innovative strategies.

On the other hand, as shown during the last 15 years of innovative actions and implementing them through EU Regional Policy- $15^{3}$, stimulation of the main actors is much harder to organize in

\footnotetext{
${ }^{1}$ Michael Porter, The Competitive Advantage of Nations, 1990.

2 "Trend Chart: innovation policy in Europe", source : http://trendehart.cordis.lu/scoreboards/scoreboard2005/index.cfin

${ }^{3}$ made based on pilot-projects between 1990-1993, Innovative Regional Strategy, and Initiatives of the Regional Informational Society started between 1994-1999, followed by the Regional Programs for Innovative Actions during 2000-2006.
} 
less developed regions because of the experience and survey restrictive as well as not understanding the innovation mechanism.

New member states did not took advantage from these innovative regional programs. However, almost 40 of their well-developed regions were supported by RIS-NAC projects projects descending from The Regional Innovative Action Plan, which was active in EU during 2000-2006.

An innovative regional system involves a certain number of actors and some resources, which interacts effectively in order to stimulate innovation in that region. This system should facilitate the following:

- Identifying available infrastructure and regional resources of knowledge and survey;

- Access to financial services, best practice exchange, knowledge exploitation (development agencies, commerce chambers, venture capital and others);

- Effective proficiency and cooperation transfer between different actors of regional development;

- In order to function, this system must have a critical mass of infrastructure and survey to be able to receive support form the Regional Policy.

However, organizing such a system is a long-term effort and can endure different experimenting. Success regions elaborate long-term policies to put in practice elements to sustain this system and to encourage the common vision for innovation as a regional development factor for all the other activities: economical, social, cultural. These strategies are often accompanied by training classes, other activities to support regional technological development and also social survey, entrepreneurship, new technology exploitation capacity and even innovation testing.

\subsection{Experience of the new Regional Operational Programs (ROP)}

Being a long-term process, innovation changes work methods and perception because every person involved has a personal roll and interest. In different situation, may be difficult to find the right way to innovate, to change perception and behavior and to find links and needed cooperation for development and dissemination.

Experimenting new approaches leads to a new roll for the ruling authorities which mostly catalyses then prescribe policies and programs. This kind of experimentations may persuade enterprises that a common approach is not a threat but an improvement for their competitiveness, they can persuade research centers that, by mixing academical excellency with open economy will ensure a poll position financially guarantied. They can convince public opinion that a well negotiated partnership between public and private sectors may be more helpful than risky.

Public authorities adopt mechanisms and build on success experiences of institutions and groups, which develop complementary products and constructive interactions.

Pilot-experiences sustained by the Regional Policy until 1990 proved the relevance of a networking approach of the Regional Innovative Strategy (RIS). Those, which can start a foreign partnership, have, usually, a major impact in the following sectors ${ }^{4}$ :

- a better perception of what should be done to promote innovation (policies, partnerships and others);

- a better cooperation between actors and a better knowledge/information flow;

- comparing between different policies implemented by some of the regions;

- development of strategies to get to an action plan with specific measures followed by specific actions;

\footnotetext{
${ }^{4}$ Ex-post evaluation RIS, RTT and RISI - innovative actions during 1994-1999; http://europa.eu.int/comm/regional_policz/docgener/evaluation/rado_fr.htm
} 
- development of a logical process: identification of priority sectors and actions to implement, testing of targeted actions, evaluation of the effect generated, exchange of best practice;

- increase in public budget allocations to innovation;

- development of a innovative culture based upon new achievement property, less reticence to change (which is now seen as an opportunity for open economies).

The new programming period of the EU Regional Policy is 2007-2013. Along this period, there is no special budget for experimentations. However, innovation is a perspicuously evolving process. It is important for regions and member states to test their new ideas and approaches in order to identify those that can contribute effectively to innovation and regional competitiveness. The European Commission recommended that Operational Programs should include a section where to describe how the experimentation will be approached indicating the management arrangements (the idea was to build a team with close connections with the Monitoring Committee) and the implementation methods (which should be different from one operation to another) (See Figure no. 1).

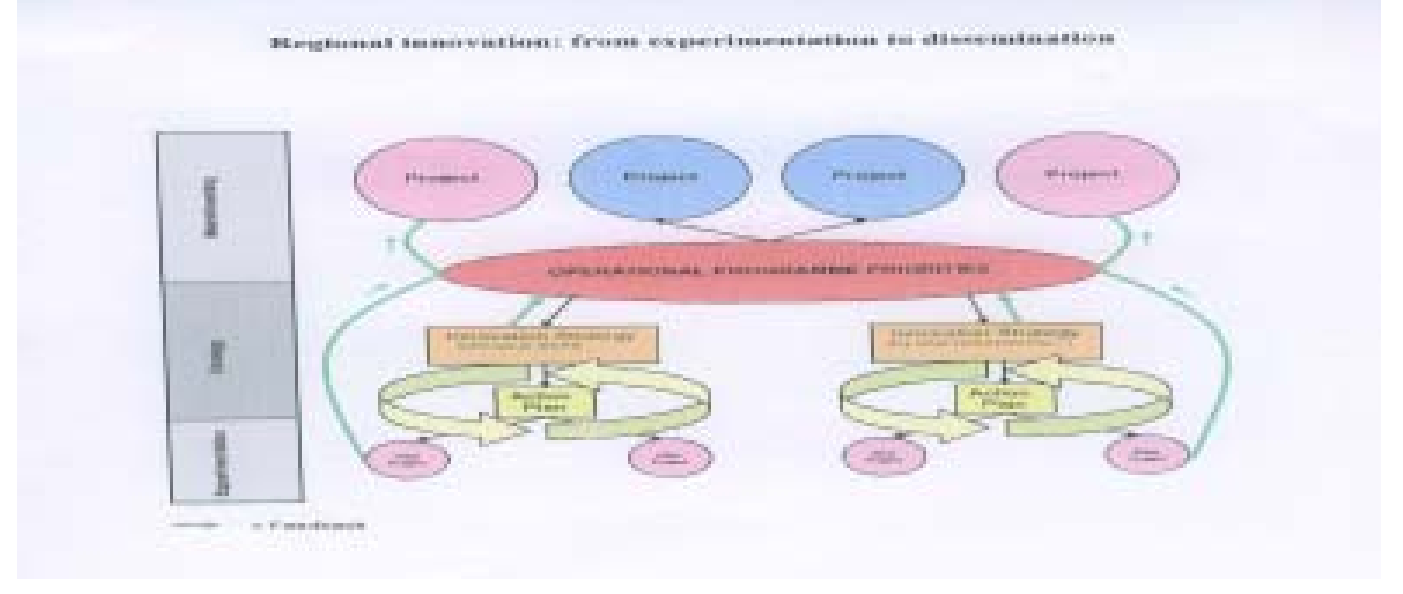

Fig. No. 1: Regional innovation: from experimentation to dissemination

Source: Regional Innovation Strategies in Newly Associated Countries 2001-2005, Directorate General for Enterprises of the European Commission

\subsection{Regional strategies - basis of a coherent system in the innovation process}

Almost every region has established development policies and programs which are reflected and supported in Operational Programs. Regions have placed on the first position innovative strategies aiming specific sectors and domains like the informational society strategy, the turistic innovation strategy, the public services strategy.

The definition of the regional innovative strategy may have as support stimulation of public and private actors around common interests and definition of different domains of opportunity where they intend to organize partnerships with other actors facing the same problems.

A study of the French Agency for Dissemination of Technological Information (ADIT) ${ }^{5}$ shows that the most advanced areas as Gotheborg, Munchen, Cambridge, Stuttgart, act through programs aiming a short number of sectors considered to be priorities in order to support their international competitivity (between four and ten, according to the activity sector), and with actions focused on the sectors concerning science and knowledge in order to obtain a better position of the region in future. This strategic approach makes possible strengthening of the strategic activities

\footnotetext{
5 "The Strategic management of regions in Europe", 2005, France.
} 
clusters focusing on added value essence produced by the region, taking action in possible competitive sectors or developing key-technologies for the regional economy (Stuttgart).

In certain regions, approaches address market losses in major sectors (finance of basic research choosing instead activation of the SME mechanisms).

Informational society strategies are true challenges because of their cross character, challenges about involving the actors in different domains: specialists in communication and information technology, local authorities, agencies, public services, trainers, social partners and others.

Innovational strategy intends to stimulate involved actors in a certain area of activity, economical or social sector, in order to achieve certain objectives (Figure 1):

- analysis of the activity sector situation in the region and comparison with other competitive regions;

- establishing sectorial objectives and priorities, justifying this choices;

- identifying and allocating fund for every sector or activity area;

- defining public intervention within multi-annual activities which to ensure actions continuity. Effectiveness of the strategy is strengthening by time scale, which allows assimilating results with influence over internal and external transparency.

Success of a region depends on the existing innovation strategy within the Regional Operational Programs, national programs and regional pre-existing programs. They support actions credibility and offer a greater power by implementing the strategy. Implementation of a correct strategy allows these regions to negotiate with national partners for a better position, which may eventually influence the national policies.

A well-managed strategy has catalytical effect on regional innovation. It may put in place a partnership based on specific objectives and include evaluation of every action to make possible policy adjustment during the programming period. This flexible approach may be easier to insert in Operational Programs 2007-2013. The Commission suggests insertion of pilot-actions which public authorities find risky financed immediately on a large scale. A proper management for common financing based on a minimum acceptable financial risk. Regional Policy must remain open to "risk" and this is possible using this methods: projection, testing, evaluation, implementation of new methods on pre-established bases.

\section{A. Regional strategies evaluation}

Testing new approaches on a regional level implies a first evaluation. This starts with an analysis of the socio-economical situation in that region. Social and economical situation is different from one region to another.

Regional evaluation for a specific sector benefits by the implication of some regional keyactors: they will identify the needs of the region and propose actions to taken for the best results possible. It is also preferable to implicate in this evaluation some financial actors.

Evaluation must combine different analysis in order to cover some aspects as follows:

1. identifying strong points/weak points, opportunities and restrictions, including comparative analysis;

2. measurement indicators for demand (needs, expectations, dangers) and offer (equipments, survey, services, financial sources and others);

Evaluation must allow defining of the most powerful sectors. Every activity sector must have a strategy which should be correlated with the regional innovation strategy.

\section{B. Regional strategies based on partnership}

Regional authorities establish the strategy based on regional needs evaluation, strong and weak points, creating a coherent framework of innovative actions. Partnership has a very important role in this stage (evaluation - projection). The partnership must comply with the needs of all 
involved actors. If it is about a public-private partnership, the implementation of the strategy will be more satisfying for a large number of enterprises that will be able to find these way new business opportunities.

\subsection{Stimulating innovation with the Regional Operational Programs 2007-2013}

Some time ago, the link between Regional Programs for Innovative Actions co-financed by RDDF and Operational Programs was not so easy because of institutional and political reasons and also because of the staging process: innovative actions programs were not implemented over the same time period as Operational programs. Some regions had the chance to learn from the innovative actions programs. However, the frame of the innovative networks between different actors and created for technological transfer (first created in Toscana region).inside the innovative programme network was first used in 2004 as a reference point for several provisions of the Unique Programming Document 2000-2006 and will be the base for any further interventions in the innovative area.

Some regions choose their innovative programme management to be inside the Regional Programme facilitating this way a great number of pilot-actions. Other regions wait until some results appear and than include it in the Operational Programme financial plan.

\subsubsection{Generalization of good practice examples inside Operational Programs 2007-2013}

The new programming period of the EU Regional Policy allows achievement of exploitation actions during implementation of the operational programs. Contrary to the previous period, this one places these actions under the same responsibility. This synchronization should facilitate results dissemination and encourage their transfer to other activity sectors inside the programme. The link with the Operational Programme should offer a strong signal of the region involvement in the innovation policy and long-term resources found.

This advantage comes with some risk. Without a specific management, the experimental approach may loose visibility and efectivity. This is the reason why the Commission suggests call for proposal, selection, monitoring and evaluation of this experimental actions and maintaining a close connection with the responsible authorities.

The Regional Operational Programs challenge consists in building a regional strategy, which may already exist or planned, and try a new approach in order to support it. The results of these experiments may contribute to changing the nature of the Regional Policy interventions, strengthening the innovative approach in all activities including traditional intervention for infrastructure projects, supporting SMEs, human resources and others.

Previous experience shows that:

1. small investments can affect on regional innovation;

2. a thorough evaluation of these new approaches shows that added value and impact are necessary to persuade on a political level and also to mobilize the regional actors;

3. requests of a participative system which associates all the involved actors and also transparency from public authorities to their partners as well as a strong involvement feeling;

4. by this process, the new organizations of the priorities inside the Operational Programme can be supported within a regional consensus.

\subsubsection{Best practice transfer to different regions and sectors}

Best practice transfer from one sector to another or from one region to another may increase the operation funding effect. In the end, different services involved sectors must communicate and agreed upon them. Establishing an authority with jurisdiction over those sectors will facilitate this transfer. Such an organism may be a regional authority or a regional development agency. The 
networks necessary for the best practice exchange bring together different actors who may contribute to the actual transfer from one sector to another.

Concerning the regional level transfer there are some mechanisms to facilitate the best practice transfer among the regions. These are:

1. innovative regional networks;

2. twinning regions;

3. study (learning)visits.

\section{Regional innovative networks}

Regions who take part in the innovation networks benefit from the international experience through the european programs and policies informations and through the influence of their EU partners. Also, they can get informations from other regions strategies and practices with close profiles and problems.

At the same time, cross-border regional cooperation projects have important contributions at the benefit of the network activities as follows:

- Every partner can compare methods, practices and effects in different institutional and cultural contexts;

- Every one can identify specific aspects of the approach, possible improvements of the current practices and new ideas stimulated by methods with positive results in other regions, even if it need some adaptation to the specific circumstances.

Today, the challenges that EU is put face to face with conduct to an intensive inter-regional cooperation in order to accelerate the innovative process for a larger number of enterprises/ organizations/ regions.

Some networks are organized around experience exchange. This can be done by organizing seminars, study visits, trainings, workshops where regions are participating for their own interest. Developing this kind of networks takes time and the relations build inside them are based on mutual trust and common interest despite any cultural or language distinction. These networks are based on strong communications and many meetings attended. Sometimes, inside networks there will be discussions about operational objectives but most of the times will be analyzed innovational strategies and policies.

From the previous experience, it can be drown the conclusion that it is necessary to comply with several conditions:

1. regions representativity is very important. It has the role to influence regional policy and must have a certain experience in this area - innovation has different effects in various domain;

2. there must be a strong motivation of the involved persons - sometime there can be years before these persons will be really prepared;

3. implicated persons must be able to communicate in many languages.

\section{Twinning regions}

Another inter-regional cooperation form to facilitate exchange of knowledge is twinning of the regions.

This type of cooperation is financially supported by EU regional policy through RIS-NAC programs. There are right now almost 40 regions which benefit over these programs and have started actions within the regional innovative strategies.

Every region in twinning with at least one other region and the programs to benefit from are already developing. The European Regional Development Found (ERDF) in RIS programs (Regional Innovation Strategies) founds these programs. Methodology is based on the following elements:

1. existence of consensus between regional key-actors; 
2. analysis of the regional innovational system;

3. development of the innovational strategies and policies on these bases.

\section{Study visits}

Study visits are organized both ways, between two regions, which desire to understand very clearly how success of experimentation can be achieved. These visits and knowledge exchange encourage regions to target new ideals and make possible diminishing of contextual discrepancies.

Those who take part in these visits must affect the region administration in order to be able to respond to the best practice established by the political authorities. The reports over these study visits are of very special importance.

Tabel no. 1.

\section{Case study: Regional Programs for Innovative Actions of different member states}

\begin{tabular}{|c|c|}
\hline Region & Innovative Strategy \\
\hline $\begin{array}{l}\text { Bretagne Region - } \\
\text { France }\end{array}$ & $\begin{array}{l}\text { Regional Programme for Innovative Actions 2003-2006 for } \\
\text { Bretagne Region is clearly related to the National Health and } \\
\text { Nutrition Programme objectives (2001-2005), which focus on } \\
\text { specific individual actions. Based on an uncertain market but with } \\
\text { high potential (agricultural produces with added value), this } \\
\text { programme aims to change the french region image, which is seen } \\
\text { as the main agricultural region in France but with a production } \\
\text { system based on mass production of traditional low added value } \\
\text { products. } \\
\text { The Programme supports nine technical centers of exploitation } \\
\text { action finance for nine products (fish, dairy, fruits, vegetables and } \\
\text { others) as well as horizontal actions (market studies and research, } \\
\text { audit, training, nutrient guide, Omega3 role in preventing cardio } \\
\text { diseases and others). This way, The Innovation Programme } \\
\text { supports development of health-nutrition cluster in Bretagne. }\end{array}$ \\
\hline $\begin{array}{l}\text { Bavaria Region - } \\
\text { Germany }\end{array}$ & $\begin{array}{l}\text { Regional Programme for Innovative Actions in Bavaria aims to } \\
\text { stimulate innovation in rural areas features by micro, medium and } \\
\text { small enterprises. It is supported by the local governance, } \\
\text { chambers of commerce and University of Passau. There were } \\
\text { organized many workshops to present measurement and } \\
\text { implications to companies. The workshop gathered together } \\
\text { regional experts, students, entrepreneurs and actors really } \\
\text { implicated in production and in decision making. Based on } \\
\text { understanding the innovative capacity, this approach helps } \\
\text { creating a real dynamic in the region. } 70 \text { projects advanced after } \\
\text { only nine months absorbing third part of the total available } \\
\text { resources and ten new enterprises wanted to join the programme. }\end{array}$ \\
\hline Scotland & $\begin{array}{l}\text { In order to sustain the Regional Programme for Innovative } \\
\text { Actions in Scotland, there was created an important partnership } \\
\text { including key-partners in the innovation support system. "Steering } \\
\text { Group" and "Development Group" Programms were build with } \\
\text { the most important local economic development agencies, other } \\
\text { regional executive programs, high education sector and private } \\
\text { sector. This partnership structure ensures meeting of all the } \\
\text { quantifiable expectations, good practices and others on regional } \\
\text { agencies level as well as on a political level. }\end{array}$ \\
\hline Rioja Region - Spain & $\begin{array}{l}\text { Regional Programme for Innovative Actions (2002-2004) for } \\
\text { Rioja Region in Spain generated a strong private sector }\end{array}$ \\
\hline
\end{tabular}




\begin{tabular}{|c|c|}
\hline & $\begin{array}{l}\text { participation with an additional financial participation of } 4.6 \text { mill } \\
\text { Euro to the } 0.6 \text { mill initially invested. Success was brought by the } \\
\text { programs dynamic management due to regional agencies and to } \\
\text { permanent contact with other companies. This programme, } \\
\text { opened to innovation and technological transfer, ensured } \\
\text { cooperation to developing new products for companies and new } \\
\text { cooperation agreements for research and technological centers on } \\
\text { regional, national and international level. }\end{array}$ \\
\hline $\begin{array}{l}\text { Barcelona } \\
\text { Metropolitan area - } \\
\text { Spain }\end{array}$ & $\begin{array}{l}\text { Under PAXIS Programme ("Pilot Action of Excellence on } \\
\text { Innovative Stat-Ups", financed by the General Directory for } \\
\text { Enterprises), the metropolitan area of Barcelona invited } \\
\text { innovation experts from Munchen, Stuttgart, Helsinki, Stockholm } \\
\text { for one week for a study visit in order to improve the innovative } \\
\text { policies. Based on the enterprises, commerce chambers, public } \\
\text { authorities and other actors interview results, the experts drawn } \\
\text { conclusions and expose it in front of over } 250 \text { participants. }\end{array}$ \\
\hline Austria Regions & $\begin{array}{l}\text { Starting 1997, Nieder Region developed a regional innovative } \\
\text { system in partnership with the Technology and Innovation Office } \\
\text { as well as regional commerce chambers. The process was staged } \\
\text { as follows: } \\
\text { During } 1997-1999 \text { - pilot - project supported cooperation } \\
\text { between all the actors involved, including SME cooperation; the } \\
\text { regional innovation strategy was elaborated. } \\
\text { International networks and a new cluster were created and } \\
\text { got financing under the Second Objective of the Unique } \\
\text { Programming Document and from INTERREG III programs; } \\
\text { For 2004-2006, inside the Regional Programme for Innovative } \\
\text { Actions begun strategy experimentation. With a strong } \\
\text { cooperation with Viena Region (started in 2002), the Excellence } \\
\text { Prize from European Commission was granted inside PAXIS } \\
\text { network for supporting creation of start-up innovative enterprises } \\
\text { in Europe. }\end{array}$ \\
\hline
\end{tabular}

Source: www.innovating-regions.org, www.ianis.net

\section{References:}

1. http://ec.europa/comm/regional_policz/index_en.htm

2. http://www.ianis.net/

3. http://www.eriknetwork.net/

4. http://trendchart.cordis.lu/

5. http://cordis.europa.eu/paxis/src/home.htm

6. http://www.evalsed.com

7. http://www.cordis.lu/innovation/en/home.html

8. http://www.cordis.lu/en/home.html

9. http://cordis.europa.eu/era/regions.htm 